\title{
The prevalence of atrial fibrillation in the catchment area of University Hospital Dubrava
}

\section{Mario Udovičić ${ }^{*}$ -Danijela Grizelj, - Mariam Samara, CHrvoje Falak, DAna Jordan, (1) Petra Vitlov, DDiana Rudan}

University Hospital Dubrava, Zagreb, Croatia
RECEIVED:

December 6, 2020

ACCEPTED:

December 18, 2020

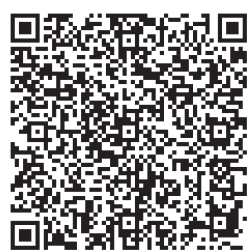

KEYWORDS: atrial fibrillation, epidemiology, prevalence.

CITATION: Cardiol Croat. 2021;16(1-2):65. | https://doi.org/10.15836/ccar2021.65

*ADDRESS FOR CORRESPONDENCE: Mario Udovičić, Klinička bolnica Dubrava, Av. Gojka Šuška 6, HR-10000 Zagreb, Croatia. / Phone: +385-98-477248 / E-mail: mario.udovicic@gmail.com

ORCID: Mario Udovičić, https://orcid.org/0000-0001-9912-2179 • Danijela Grizelj, https://orcid.org/0000-0002-8298-7974 Mariam Samara, https://orcid.org/0000-0003-2384-273X • Hrvoje Falak, https://orcid.org/0000-0002-6502-683X Ana Jordan, https://orcid.org/0000-0001-5610-6259 • Petra Vitlov, https://orcid.org/0000-0001-6983-1409 Diana Rudan, https://orcid.org/0000-0001-9473-2517

|||||||||||||||||||||||||||||||||||||||||||||||||||||||||||||||||||||||||||||||||||||||||||||||||||||||||||||||||||||||||||||||||||||||

Goal: The aim of this study was to evaluate the community-based prevalence of atrial fibrillation (AF) in a geographically well-defined population in the central part of Croatia.

Methods: We searched hospital electronic health records of Clinic of Internal Medicine (IMD) and Emergency Department (ED) of University Hospital Dubrava (UHD) for patients older than 20 years of age diagnosed with AF in the period from January 1, 2007 to January 1, 2017. We then eliminated all the patients who have died before 2017 or did not have residence within the official catchment area.

Results: Of the 125596 patients analyzed, 14781 were diagnosed with AF; of these 5086 were alive on January 1, 2017 and residing within the official catchment area of UHD, which meant that the overall prevalence of AF was $2.0 \%$. The prevalence increased with age from $4.3 \%$ in patients over 50 years of age to $13.0 \%$ in those over 80 years. It was higher in men than in women in all age groups, while $90.8 \%$ of the population were at high risk of stroke ( $\geq 2$ points) according to CHA2DS2-VASc score.

Conclusion: Within our population, we identified a very high community-based prevalence of AF, and a very large portion of patients with indication for OAC prophylactic therapy of AF. The prevalence was strongly associated with increasing age and male gender. ${ }^{1}$

LITERATURE IIIIIIIIIIIIIIIIIIIIIIIIIIIIIIIIIIIIIIIIIIIIIIIIIIIIIIIIIIIIIIIIIIIIIIIIIIIIIIIIIIIIIIIIIIIIIIIIII

1. Andersson P, Löndahl M, Abdon NJ, Terent A. The prevalence of atrial fibrillation in a geographically well-defined population in northern Sweden: implications for anticoagulation prophylaxis. J Intern Med. 2012 Aug;272(2):170-6. https://doi.org/10.1111/j.1365-2796.2012.02519.x 